\title{
Identification of a phenoloxidase- and melanin-dependent defence mechanism in Achatina fulica infected with Angiostrongylus vasorum
}

Aytube Lucas Coaglio ${ }^{1}$, Mônica Alves Neves Diniz Ferreira², Walter dos Santos Lima ${ }^{1}$ and Cíntia Aparecida de Jesus Pereira ${ }^{1 *}$

\begin{abstract}
Background: Angiostrongylus vasorum has different freshwater aquatic and terrestrial gastropod molluscs as an intermediate host, e.g. Arion spp. The mollusc Achatina fulica is a danger to public health, given the large diversity of nematodes utilizing it as an intermediate host, such as the parasites of the genus Angiostrongylus, of importance in human and veterinary medicine. Achatina fulica has been shown to have an excellent capacity for maintaining outbreaks and natural infections with A. cantonensis in Asia. Within the mollusc, the nematode parasites activate haemocytes and/or haemolymph factors and in some invertebrates, phenoloxidase (PO), that induces the release of toxic elements and eliminates the parasites. Despite the importance of $A$. fulica in the life-cycle of nematodes, little is known regarding the defence mechanisms involving PO in molluscs infected with nematodes. Here, the presence of $\mathrm{PO}$ and nitric oxide (NO) in the haemolymph and haemocytes of A. fulica infected with first-stage (L1) larvae of Angiostrongylus vasorum was evaluated, together with the presence of melanin in the cephalopod mollusc tissue.
\end{abstract}

Results: An increase in $\mathrm{PO}$ at one day post infection (dpi), in comparison with the control using the substrates L-tyrosine $\left(F_{(4,90)}=6.73, P=0.00006\right), \mathrm{L}-\mathrm{DOPA}\left(F_{(4,90)}=22.67, P=0.02\right)$ and p-phenylenediamine (PPD) $\left(F_{(4,90)}=27.58, P=0.0019\right)$, was observed. PO increase coincided with the presence of melanin in the cephalopodal tissue. At $8 \mathrm{dpi}$, PO activity, compared to L-DOPA $\left(F_{(4,90)}=22.67, P=0.00002\right)$ and PPD $\left(F_{(4,90)}=27.58, P=0.079\right)$ decreased, while melanin increased. At $13 \mathrm{dpi}$, PO decreased with PPD $\left(F_{(4,90)}=27.58, P=0.000015\right)$ and also the amount of melanin observed in histology. At 30 dpi, PO increased along with the substrates L-DOPA and PPD, while melanin decreased. NO levels increased until 8 dpi, and decreased after 13 dpi.

Conclusions: To our knowledge, this is the first study that illustrates PO activity in a helminth-infected A. fulica and provides the first observation of an L-tyrosine dependent PO activity in molluscs infected with A. vasorum. This work suggests that PO pathway may help to control A. vasorum infection in A. fulica.

Keywords: Angiostrongylus vasorum, Achatina fulica, Phenoloxidase, Melanin, Innate immune defence

\footnotetext{
* Correspondence: cintiajp@icb.ufmg.br

${ }^{1}$ Departamento de Parasitologia, Instituto de Ciências Biológicas,

Universidade Federal de Minas Gerais, Belo Horizonte, Brazil

Full list of author information is available at the end of the article
} 


\section{Background}

Angiostrongylus vasorum parasitizes pulmonary arteries in domestic and wild Canidae and has terrestrial molluscs as intermediate hosts [1-6]. The molluscs are infected with first-stage (L1) larvae eliminated via the dogs' faeces. Inside the mollusc, L1 go through two moults to become second- (L2) and third-stage (L3) larvae, the latter being infective to the definitive hosts [7].

The mollusc intermediate host is capable of mounting a cellular immune response to parasite infection via factors soluble in the haemolymph that activate haemocytes. In addition, elements of the acellular fraction of the haemolymph can also damage the parasites' structures $[8,9]$. In some bivalves, following the recognition and encapsulation of the pathogens, the phenoloxidase (PO) pathway responsible for melanisation is activated, as well as phagocytosis and nodulation, which can sometimes result in parasite elimination [10].

PO exists in the haemolymph in its inactive form (proPO) and is activated by external components of microorganisms such as $\beta$-1,3-glucans [11] and lipopolysaccharides (LPS) [12]. These compounds induce the cleavage of proPO into PO by endogenous serine proteases [13]. Then, PO catalyses the hydroxylation of monophenols such as the amino acid tyrosine to o-diphenol (DOPA or DOPAmine), followed by their oxidation to o-quinones (DOPAquinone and DOPAminequinone) [14, 15]. At the end of the cascade, the dark pigment melanin is formed, thereby contributing to the asphyxiation of the pathogen [16].

POs are copper-binding proteins including tyrosinases (EC 1.14.18.1), catecholases (EC 1.10.3.1), and laccases (EC 1.10.3.2), and play a vital role in the immunological defence mechanism of Pacific oyster [17]. All the three types of PO can oxidise o-diphenols, such as L-3,4-dihydroxyphenylalanine (L-DOPA, catecholase activity). However, only the tyrosinases can hydroxylate monophenols such as L-tyrosine (monophenolase activity), and only laccases can oxidise $\mathrm{m}$ - and p-diphenols, or aromatic compounds containing amine groups such as p-phenylenediamine (PPD; laccase activity) $[17,18]$.

Melanin deposition around the pathogens, or in the pathogens themselves, is formed during the oxidation and polymerisation of phenols. The cytotoxic molecules generated in this process include reactive oxygen (ROS) and nitrogen (RNS) species and quinoids, which are intermediates of melanin. Additionally, an increase in the production of nitric oxide (NO), an effector molecule very effective against invasive organisms, occurs in immunoreactive hosts $[19,20]$.

Despite its importance as an intermediate host of Angiostrongylus cantonensis in areas endemic for angiostrongylosis such as Asia and South America [21-26], little is known regarding the innate immune system of $A$. fulica. The role of the PO pathway in controlling infection by nematode parasites is still poorly understood in molluscs and elucidating this process is crucial for understanding the defence mechanisms present in this intermediary host. Achatina fulica is less susceptible to A. vasorum in comparison with other molluscs and can be infected in laboratory conditions [6]. Here, we used A. fulica infected with $A$. vasorum to measure NO levels and characterise PO activity in the soluble fractions of the haemolymph using the substrates L-tyrosine, L-DOPA, and PPD. Additionally, we verified the occurrence of melanin in the cephalopodal tissue of $A$. fulica.

\section{Methods \\ Origin of the parasites and molluscs}

A total of 240 specimens of $A$. fulica with an average shell length of $30 \mathrm{~mm}$ bred in the Veterinary Helminthology Laboratory of the Federal University of Minas Gerais (LabHelVet-ICB-UFMG) were individually infected with 1000 L1 of A. vasorum obtained from dog faeces using the Baermann technique [2]. The strain used was first isolated from a dog in Caratinga, Minas Gerais, by Lima et al. [27].

L1 were added to $2 \mathrm{ml}$ of tap water and placed in a polystyrene container $(4 \times 5 \mathrm{~cm})$. The molluscs were individually immersed in the suspension for $24 \mathrm{~h}$. The container was sealed with gauze and adhesive tape. Afterwards, the molluscs were transferred to a maintenance tank containing lettuce, water, and autoclaved soil. The L1 that remained in the polystyrene containers were counted to estimate the infection rate [8].

\section{Collection of haemolymph}

The haemolymph was collected according to the changes of stages of $A$. vasorum in A. fulica; these stages changes are described according to [6]. The days post infection (dpi) used in the experiment for recovering $A$. vasorum larval stages were 1, 8, 13 and $30 \mathrm{dpi}$, for recovering L1, L1 to L2, L2 to L3 and L3 stage, respectively. The larval stages were identified using the descriptions of Bessa et al. [28], Barçante et al. [2] and Coaglio et al. [6].

For removal of haemolymph, the shell was disinfected with $70 \%$ alcohol and dried on absorbent paper. Then, in the heart region, the shell was pierced with a mini drill (Sigma-Aldrich, Darmstadt, Germany), and the haemolymph was collected by cardiac puncture with a $1000 \mu \mathrm{l}$ insulin syringe (Manoject 50 unit) and transferred for a $12 \mathrm{ml}$ polypropylene plastic tube in an ice bath. Approximately $200 \mu \mathrm{l}$ of haemolymph was collected per mollusc and added to the pool of the group, keeping the control and infected pools separated. Samples were collected from 20 molluscs per group, 10 controls and 10 infected, for each day analyzed. The experiments were repeated three times with other snails of the same lineage.

Initially, $\mathrm{pH}$ and osmolarity of $A$. fulica haemolymph in the control group were evaluated to analyze the best 
haemolymph-like buffer solution, which would allow the study of the internal defence system in A. fulica. It was noted that $\mathrm{pH}$ and osmolarity of haemolymph were $\mathrm{pH} 7.2$ and $160 \mathrm{mOsm} / \mathrm{kg}$, respectively. Thereafter, PBS solution was standardised with the osmolarity and $\mathrm{pH}$ of A. fulica $\left(\mathrm{NaCl}\right.$ at $71 \mathrm{mM}, \mathrm{KCL}$ at $2.7 \mathrm{mM}, \mathrm{KH}_{2} \mathrm{PO}_{4}$ at 1.4 $\mathrm{mM}$, and $\mathrm{Na}_{2} \mathrm{HPO}_{4}$ at $4.3 \mathrm{mM}, \mathrm{pH} 7.2$ ).

The total haemolymph of each group was centrifuged at $80 \times g$ for $10 \mathrm{~min}$ at $4{ }^{\circ} \mathrm{C}$ in a $15 \mathrm{ml}$ polystyrene vial. The supernatant (acellular fraction) was used for the analysis of $\mathrm{PO}$ and $\mathrm{NO}$ concentration. The haemocytes (cellular fraction) were washed $4 \times$ with PBS by centrifugation at $80 \times g$ for $10 \mathrm{~min}$ at $4{ }^{\circ} \mathrm{C}$. The viability of the cells was observed by counting in a hemocytometer after a 1:10 dilution in 0.4\% trypan blue (Sigma-Aldrich) [9]. The haemocytes were transferred to $12 \mathrm{ml}$ polypropylene tubes, kept on ice and sonicated for cell lysis. We used three cycles of sonication for $30 \mathrm{~s}$ each, with a one-minute interval on ice between the cycles. The haemocyte lysate was centrifuged at $1500 \times g$ for $10 \mathrm{~min}$ at $4{ }^{\circ} \mathrm{C}$, and the supernatant kept on ice for analysis of PO.

\section{Enzymatic activity of phenoloxidase}

Both the acellular fraction and the haemocyte lysate were subjected to a similar analysis of PO. Three substrates specific for PO enzymes were tested: (i) L-tyrosine (monophenol; Sigma-Aldrich) metabolized by tyrosinase only; (ii) L-DOPA (o-diphenol; Sigma-Aldrich) metabolized by the enzymes catecholase, tyrosinase and laccase; and (iii) pphenylenediamine (PPD; p-diamine; Sigma-Aldrich) metabolized by laccase only [15].

We used $10 \mathrm{mM}$ of L-DOPA (3-4-dihydroxy-L-phenylalkaline) (D9628, Sigma-Aldrich), L-tyrosine (CAS number 60-18-4, Sigma-Aldrich), and PPD (CAS number 10650-3, Sigma-Aldrich) diluted in PBS immediately before the experiment to avoid oxidation.

One-hundred microlitres of cell-free haemolymph, $50 \mu \mathrm{l}$ of substrate solution, and $50 \mu \mathrm{l}$ of PBS (total volume of $200 \mu \mathrm{l}$ ) were added to each well into a 96-well microtiter plate. As controls, we used $50 \mu \mathrm{l}$ of substrate solution with $150 \mu \mathrm{l}$ PBS. For each treatment, we tested samples, controls, and blanks (200 $\mu \mathrm{l}$ of PBS) in triplicate.

The reaction kinetics were measured for $2 \mathrm{~h}$. Readings were performed every $20 \mathrm{~s}$ at $28^{\circ} \mathrm{C}$ in a microplate reader (VersaMax Tunable Microplate reader, Molecular Devices, Sunnyvale, CA), using $\lambda=490 \mathrm{~nm}$ for L-tyrosine and LDOPA, and $\lambda=465 \mathrm{~nm}$ for PPD. The results were plotted using the maximum reaction speed (i.e. the increase in the absorbance/min), according to Alves et al. [29].

\section{NO dosage in Achatina fulica}

NO dosage in the acellular fraction of A. fulica was determined by measuring the concentration of nitrite $\left(\mathrm{NO}_{2}\right)$ using the Griess test. Fifty microliter aliquots of the samples were allocated to a 96-well plate (Falcon', BD lab., New York, USA) and $50 \mu \mathrm{l}$ of Griess reagent were added to each well. Following $10 \mathrm{~min}$ of reaction at room temperature, the reading was performed in a spectrophotometer at $\lambda=570 \mathrm{~nm}$.

\section{Histology and parasitic load}

Histological techniques also analyzed each A. fulica specimen used for haemolymph extraction. A $2 \mathrm{~cm}$ tissue fragment was separated from the shell and fixed in Milloning [30]. Tissues were dehydrated through an alcohol series, cleared with xylol, and embedded in paraffin [31]. Histological sections of $5 \mu \mathrm{m}$ thickness were mounted on histological slides and stained with haematoxylin-eosin [32] and Fontana-Masson [33] and then examined using an Olympus BX41 microscope coupled to an Olympus DP12 digital camera. The remaining mollusc tissue was digested with $1 \% \mathrm{HCl}$ and pepsin (VETEC, 100 units $/ \mathrm{ml}$ ) at $37^{\circ} \mathrm{C}$ to estimate the parasite load [6].

\section{Statistical analysis}

$\mathrm{PO}$ activity and NO production were analyzed by a oneway ANOVA, followed by the Tukey's post-hoc test. Differences at $P<0.05$ were considered statistically significant.

\section{Results}

\section{Parasite load}

The average proportion of $\mathrm{L} 1$ remaining in the containers used for infection was $25 \%$. Thus, the average number of L1 that penetrated the molluscs was 750 . Following the collection of haemolymph and digestion with $1 \%$ $\mathrm{HCl}$-pepsin, we recovered larvae from all the molluscs. Percentages varied from 8 to $25 \%$ for L1, $7-19 \%$ for L2, and $12-30 \%$ for L3. Throughout the experiment, no mortality of $A$. fulica was observed.

\section{Phenoloxidase activity}

We observed PO activity with the substrates L-DOPA, L-tyrosine, and PPD. Figure 1 illustrates PO concentration in the haemolymph of $A$. fulica infected with $A$. vasorum and controls.

PO levels with all the substrates peaked at $1 \mathrm{dpi}$, in comparison with the control, using the substrates LDOPA $\left(F_{(4,90)}=22.67, P=0.02\right)$, L-tyrosine $\left(F_{(4,90)}=6.73\right.$, $P=0.00006)$ and PPD $\left(F_{(4,90)}=27.58, P=0.0019\right)$ was observed (Fig. 1a, c).With activity reduction at 8 dpi for the substrates L-DOPA and L-tyrosine (2.0 and 1.55 times lower than that observed at $1 \mathrm{dpi}$, respectively) while activity with PPD remained similar. And PO activity control compared to L-DOPA $\left(F_{(4,90)}=22.67, P=0.00002\right)$ decreased, while in $\operatorname{PPD}\left(F_{(4,90)}=27.58, P=0.079\right)$ increased (Fig. 1a and c). At 13 dpi, PO levels with the substrates LDOPA and L-tyrosine remained stable, while activity with PPD decreased (1.73 times lower than that 


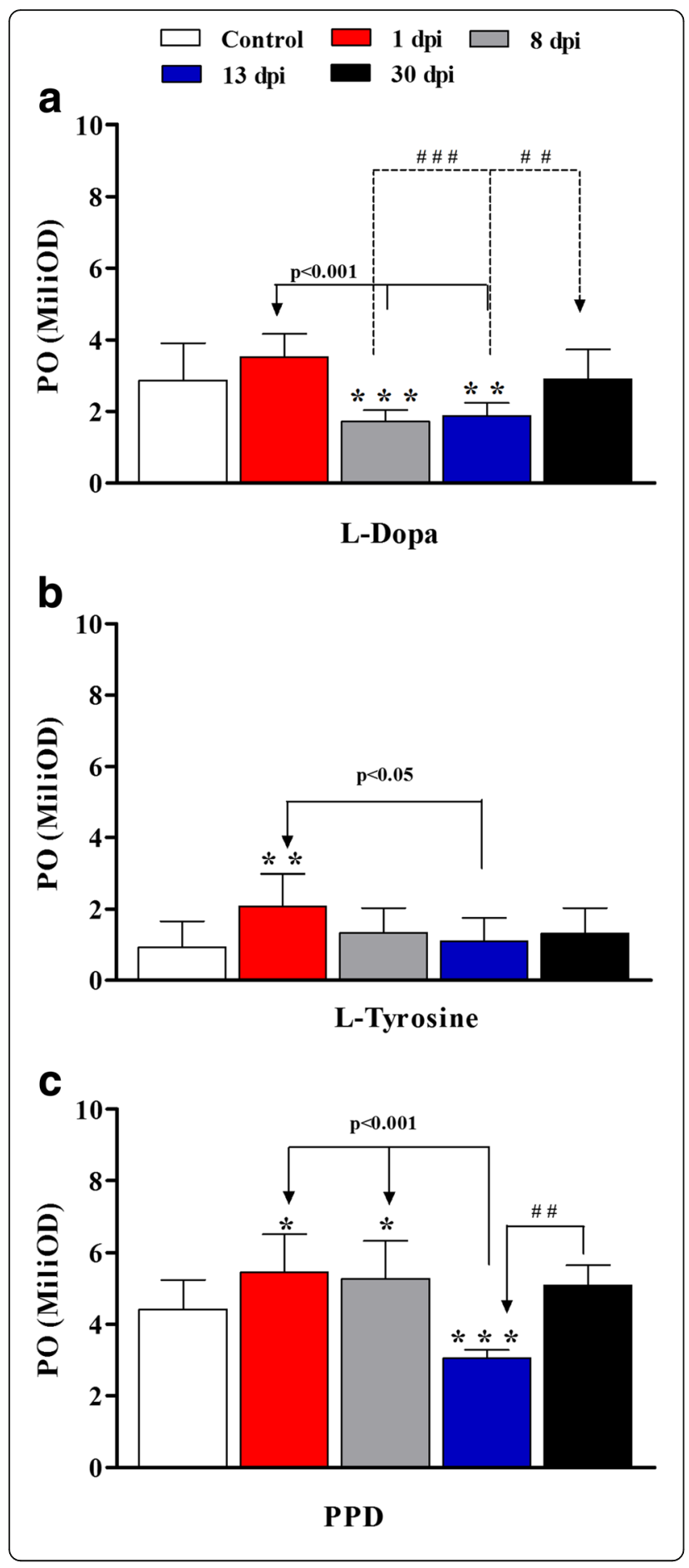

Fig. 1 Phenoloxidase (PO) activity in Achatina fulica infected with 750 first-stage (L1) larvae of Angiostrongylus vasorum, tested with the substrates L-DOPA L-Tyrosine and p- phenylenediamine (PPD). Each column represents mean and standard deviation of $\mathrm{PO}$. a Analysis with the substrate L-DOPA: ${ }^{*} P<0.001$ and ${ }^{*} P<0.01$ statistical significance of $8 \mathrm{dpi}$ and $13 \mathrm{dpi}$, respectively, in comparison with the control; solid arrow $(P<0.001), 8 \mathrm{dpi}$ and $13 \mathrm{dpi}$ in comparison with $1 \mathrm{dpi}$; dashed arrow \#\#\# ( $P<0.001), 30$ dpi in comparison with $8 \mathrm{dpi}$; and \#\# $(P<0.01)$, $30 \mathrm{dpi}$ in comparison with $13 \mathrm{dpi}$. b Analysis with the substrate LTyrosine: ${ }^{*} P<0.01,1$ dpi in comparison with the control; solid arrow $(P<0.05), 13$ dpi in comparison with 1 dpi. c Analysis with the substrate PPD; ${ }^{*} P<0.05$ and ${ }^{* *} P<0.001,1 \mathrm{dpi}, 8 \mathrm{dpi}$, and 13 dpi in comparison with the control; solid arrow $(P<0.001), 13$ dpi in comparison with 1 dpi and 8 dpi; \#\# $P<0.01,30$ dpi in comparison with $13 \mathrm{dpi}$

observed at $8 \mathrm{dpi}$ ) and $\mathrm{PO}$ decreased in L-DOPA $\left(F_{(4,90)}=22.67, P=0.00029\right)$ and PPD $\left(F_{(4,90)}=27.58, P=\right.$ 0.000015 ) in relation to control (Fig. 1a and c). At $30 \mathrm{dpi}$, PO levels increased with the substrates L-DOPA and PPD (1.63 times higher than at $13 \mathrm{dpi}$ ) and activity with Ltyrosine remained constant, there was no statistical difference in relation to the control (Fig. 1a and c). Activity with the substrate PPD was the highest in the cell-free haemolymph at all times analyzed.

The populations of haemocytes showed 95\% viability before sonication, and lysate haemocytes of A. fulica showed no PO activity.

\section{NO levels in Achatina fulica haemolymph during parasite infection}

NO levels were indirectly estimated in the soluble fraction of A. fulica haemolymph through the measurement of $\mathrm{NO}_{2}$ (Fig. 2). Until $13 \mathrm{dpi}$, the non-infected molluscs showed lower amounts of $\mathrm{NO}$ in the haemolymph $(0.018 \mathrm{nM})$ in comparison with those infected; but at 30 dpi, NO levels were lower than those observed for controls. The peak of $\mathrm{NO}$ was registered at $8 \mathrm{dpi}(0.12 \mathrm{nM})$ and was 6.5 times higher than the control $\left(F_{(4,24)}=94.59\right.$, $P=0.003687)$. The amount of NO started to decrease at 13 dpi but was still significantly higher than the control $\left(F_{(4,24)}=94.59, P=0.001\right)$. At $30 \mathrm{dpi}$, NO levels were 15 times lower than the levels observed at $8 \mathrm{dpi}$ (peak).

\section{Histology}

The melanin presence in the cephalopod tissue of $A$. fulica in molluscs of the control (Fig. 3a) and infected groups (Fig. 3b-e) was confirmed performing FontanaMasson staining, which is specific for melanin. At $1 \mathrm{dpi}$ a cellular infiltrate surrounding the $A$. vasorum larvae with melanin deposition was observed (Fig. 3b). In this tissue, L1 were observed wrapped by the cellular infiltrate and a discrete presence of melanin in the surroundings (Fig. 3b). At $8 \mathrm{dpi}$, the cellular infiltrates increased around the $A$. vasorum larvae, and the L2 deposition of melanin in the tissues seemed to be more pronounced in comparison 


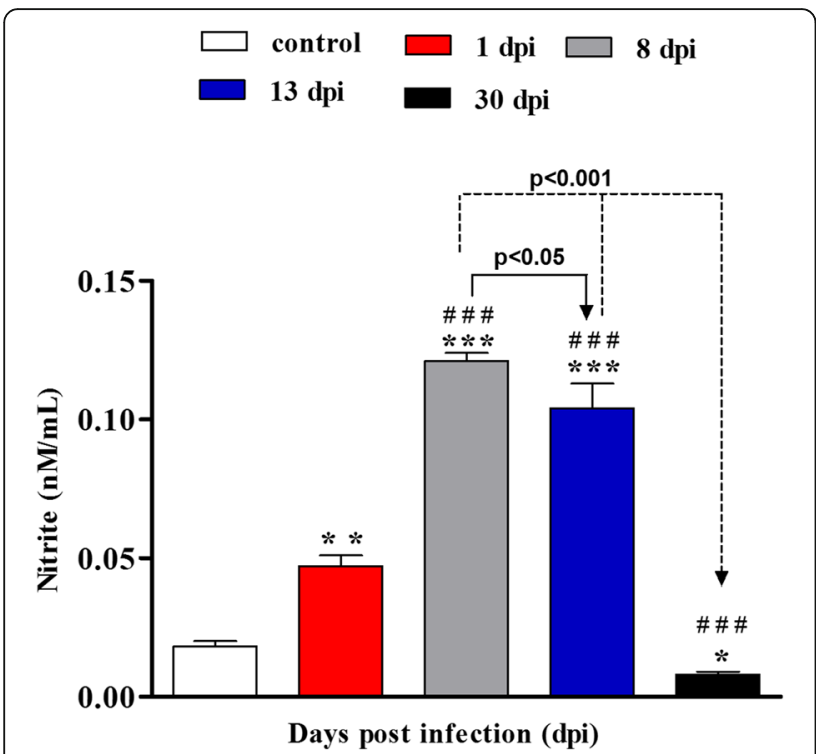

Fig. 2 Nitrite contents in the soluble fraction of the haemolymph of Achatina fulica during Angiostrongylus vasorum infection. Each column represents mean and standard deviation of the nitrite in haemolymph. ${ }^{*} P<0.001,{ }^{* *} P<0.001$ and ${ }^{*} P<0.05$ represent the statistical significance of $1 \mathrm{dpi}, 8 \mathrm{dpi}, 13 \mathrm{dpi}$, and $30 \mathrm{dpi}$, respectively, in comparison with the control; \#\#\# $P<0.001,8$ dpi, 13 dpi, and 30 dpi in comparison with 1 dpi; arrows $(P<0.05$ and $P<0.001), 13$ dpi and 30 dpi, respectively, in comparison with 8 dpi

with what was observed at $1 \mathrm{dpi}$ (Fig. 3c). At $13 \mathrm{dpi}$, when $\mathrm{L} 2$ become $\mathrm{L} 3$, a reduction in melanin deposition on the tissue and surrounding the larvae occurred (Fig. 3d). We observed a decrease of the cellular infiltrate surrounding L3 A. vasorum at $30 \mathrm{dpi}$, and on this day, the melanin deposition decreased comparing to the other days of infection (Fig. 3e).

Through hematoxylin-eosin staining allowed to verify the presence of melanin on the outside of the cells in the infiltrate (Fig. 4a). The presence of melanin crystals in the tissue on every analyzed day of this study, as represented at $1 \mathrm{dpi}$ (Fig. $4 \mathrm{~b}$ ), was confirmed.

\section{Discussion}

In the present study, we demonstrated that the soluble fractions of the haemolymph of A. fulica had PO activity and showed the presence of melanin in the cephalopod tissue; however, snails infected with $A$. vasorum showed higher PO activity on some days. PO enzymatic activity was detected both with the non-specific substrate LDOPA, which metabolizes catecholase, laccase and tyrosinase, and the substrates specific for laccase (PPD) and tyrosinase (L-tyrosine).

Very few studies have explored PO activity in molluscs, and most models involving molluscs do not have PO activity with the substrate L-tyrosine [15, 34]. Activity with this specific substrate is frequently observed in insects such as Drosophila melanogaster [14, 35, 36]. Here, we demonstrated mollusc reactivity to the substrate L-tyrosine, and melanin was circulating in the haemolymph spaces, surrounding the parasites, as observed in the melanotic capsules of insects. The staining intensity of the melanin deposition, however, differed from that observed in insects $[20,37,38]$. Unlike some populations of insects [36], melanin of $A$. fulica was not detected inside the circulating haemocytes, nor in the cells infiltrated in the tissues analyzed.

PO activity in the haemolymph at $1 \mathrm{dpi}$, detected with the substrates L-DOPA, L-tyrosine and PPD, coincided with the beginning of the detection of melanin in the epithelium. However, a lower amount of melanin was observed in the connective tissue in the surroundings of L1, where cells migrated.

At $8 \mathrm{dpi}$, the levels of $\mathrm{PO}$ detected in the haemolymph decreased with L-DOPA and L-tyrosine substrates, in this day the moult from L1 to L2 may modulate PO activity through the antigens produced during the moult. The melanin and the cellular infiltrate increased in the connective tissue surrounding L2, suggesting that this tissue could lead to a mechanical contention of the parasite.

Melanin circulates in the tissue infiltrate through the haemolymph spaces and, during the activation of $\mathrm{PO}$ pathway in insects, cytotoxic elements such as quinones and oxygen and nitrogen derivates are produced to boost the destruction of the pathogens' tegument $[20,39,40]$. We suggest that a similar mechanism may occur in our model, as A. fulica presented the highest levels of NO in the haemolymph at $8 \mathrm{dpi}$.

The transformation from L2 to L3 seems to also negatively interfere with PO activity at $13 \mathrm{dpi}$ for all the three substrates tested, and particularly PPD. At this interval, the levels of NO and circulating melanin in the epithelial and connective tissues and the cellular infiltrate next to the parasite started to decrease.

Finally, at $30 \mathrm{dpi}$, the modulation of the L-tyrosinedependent PO pathway continued at the same level as the previous days of infection, whereas $\mathrm{PO}$ levels increased with L-DOPA and PPD. The PO oscillations observed during larval development may occur due to the detection of products released by L1 and L3 when $A$. vasorum penetrates and exits the A. fulica tissues [41, 42]. Another factor to be considered is the activation of PO pathway in the nematode cuticle as described by Brivio et al. [43]. In insect Diatraea flavipennella infected with the parasitoid Cotesia flavipes, modulation was observed in $\mathrm{NO}$ and $\mathrm{PO}$ levels throughout parasite infection [20]. However, further studies are needed to a better understand this mechanism.

The decrease of $\mathrm{NO}$ at $30 \mathrm{dpi}$ in comparison to the control may be due to the association of biological characteristics of L3 of Angiostrongylus spp. that exhibits motility and allows its active output from the granuloma 

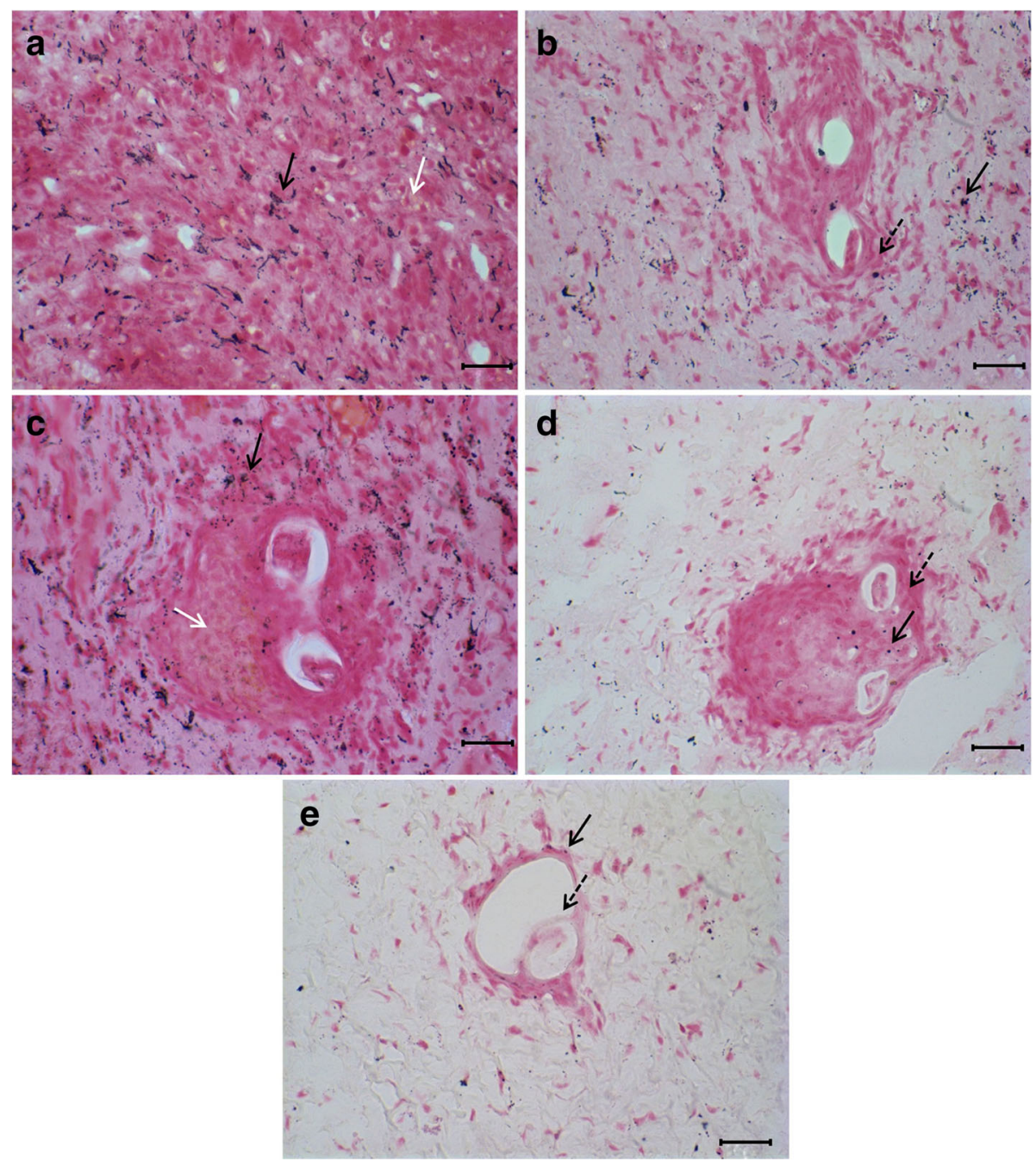

Fig. 3 Histological sections of the cephalopodal region of Achatina fulica. a Control, melanin deposition (black arrow) and melanin production (white arrow) in the tissue. b 1 dpi, L1 surrounded by cellular infiltrate (dashed arrow) with the presence of melanin (black arrow). c 8 dpi, the presence of melanin (black arrow) and melanin production (white arrow). d 13 dpi, larvae involved in cellular infiltrate (dashed arrow), with a low amount of melanin (black arrow) in the surroundings. e $30 \mathrm{dpi}$, larvae involved by less dense cellular infiltrate (dashed arrow) and low amount of melanin in the surroundings (black arrow). Scale-bars: $25 \mu \mathrm{m}$
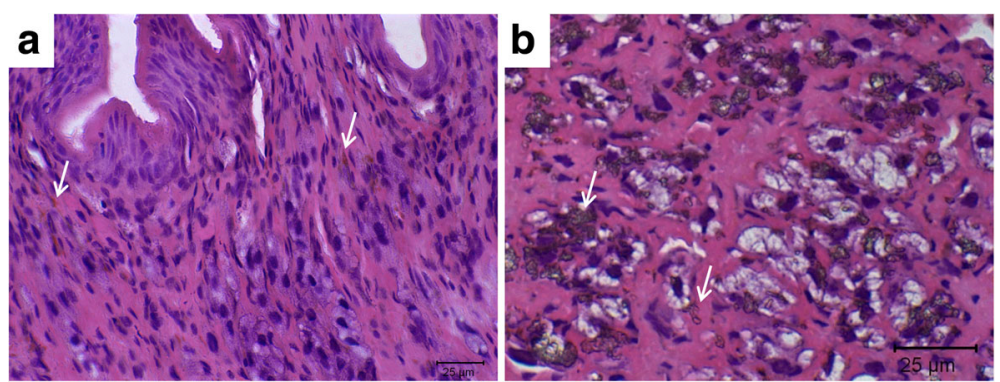

Fig. 4 Histological sections of the cephalopodal region of Achatina fulica. a Melanisation spots in the tissue of Achatina fulica control (white arrows). b Tissue at $1 \mathrm{dpi}$, presence of melanin crystals in tissue (white arrows). Scale-bars: $25 \mu \mathrm{m}$ 
in molluscs tissues [44, 45]. Also, L3 eliminating excretory/secretory products may contribute to increase or decrease the activation levels of the innate immune defence system of molluscs [42, 46]. In Biomphalaria tenagophila infected with $A$. vasorum at $30 \mathrm{dpi}$, a decrease in NO level was observed in relation to the control group [8].

Here, we suggest that $A$. fulica presents an innate immune defence mechanism based on PO pathway. According to Allam \& Raftos [47], this mechanism could be important for pathogen recognition. At $1 \mathrm{dpi}$, when the melanin in the tissue close to the parasite is still unremarkable, cytotoxic products, such as NO, start to increase in the soluble fractions of the haemolymph, thus indicating that recognition of $A$. vasorum may be taking place. Le Clec'h et al. [15] observed that Biomphalaria glabrata infected with Schistosoma mansoni presents laccase-dependent PO activity but did not associate the activation of this pathway with the susceptibility to the parasite. The oscillations in the levels of PO, tissue melanin, and $\mathrm{NO}$ observed in our model may contribute to the control of the infection. Indeed, Coaglio et al. [6] recovered only $8 \%$ of L3 in A. fulica infected with $A$. vasorum, in contrast with the over $80 \%$ recovery of L3 reported by Mozzer et al. [3] and Barçante et al. [45] in Omalonyx matheroni and B. glabrata.

Unlike the arthropods (insects and crustaceans) that have PO located mainly in the haemocytes, we did not detect a response of $\mathrm{PO}$ in the populations of haemocytes of $A$. fulica during the infection with $A$. vasorum, similar to previous observations in B. glabrata [15] and in haemocytes of Lymnaea stagnalis infected with Plagiorchis sp. [34]. In insects such as D. melanogaster, PO is located in the crystal cells and lamellocytes [36, 48].

L-tyrosine-dependent PO activity is frequent in arthropods [36, 49]. To the best of our knowledge, we show herein for the first time, its presence in the soluble fractions of the haemolymph of A. fulica, which may explain the lower susceptibility of $A$. fulica to Angiostrongylus spp. $[6,50,51]$.

\section{Conclusions}

We suggest that the cytotoxic products, such as NO, released in the PO pathway, may play a role in controlling the infection inside the mollusc. Further studies will be needed to understand the PO-dependent defence mechanisms in this terrestrial mollusc.

\footnotetext{
Abbreviations

dpi: day(s) post-infection; L1: first-stage larvae; L2: second-stage larvae; L3: third-stage larvae; LPS: lipopolysaccharides; NO: nitric oxide;

PO: phenoloxidase; PPD: p-phenylenediamine; proPO: phenoloxidase inactive form; RNS: species reactive nitrogen; ROS: species reactive oxygen
}

\section{Acknowledgements}

The authors would like to thank Dr Nelder de Figueiredo Gontijo from the Department of Parasitology, Instituto de Ciências Biológicas,
Universidade Federal de Minas Gerais, Brazil, for providing the reagents for phenoloxidase analysis (L-DOPA and L-Tyrosine). Moreover, we would like to thank Dr Deborah Negrão Corrêa from the Department of Parasitology, Instituto de Ciências Biológicas, Universidade Federal de Minas Gerais, Brazil for sharing the laboratory and its equipment.

\section{Funding}

We thank the funded by the Minas Gerais Research Foundation (Fundação de Amparo à Pesquisa do Estado de Minas Gerais - FAPEMIG) (WSL, grant number 18898) and the National Council for Scientific and Technological Development (Conselho Nacional de Desenvolvimento Científico e Tecnológico - CNPq) (WSL, grant number 164813/2013-6).

\section{Availability of data and materials}

All data generated or analyzed during this study are included in this published article.

\section{Authors' contributions \\ Conceived and designed the research: ALC and CAJP. Performed the experiments: ALC and CAJP. Analyzed the data: ALC, CAJP and MANDF. Wrote and reviewed the paper: ALC, CAJP and WSL. All authors read and approved the final manuscript.}

\section{Ethics approval and consent to participate}

The experiment was approved by the Ethics Committee for Animal Research of the Federal University of Minas Gerais (CETEA/UFMG), under the protocol number 147/2011.

\section{Consent for publication}

Not applicable.

Competing interests

The authors declare that they have no competing interests.

\section{Publisher's Note}

Springer Nature remains neutral with regard to jurisdictional claims in published maps and institutional affiliations.

\section{Author details}

${ }^{1}$ Departamento de Parasitologia, Instituto de Ciências Biológicas, Universidade Federal de Minas Gerais, Belo Horizonte, Brazil. ²Departamento de Patologia Geral, Instituto de Ciências Biológicas, Universidade Federal de Minas Gerais, Belo Horizonte, Brazil.

Received: 7 November 2017 Accepted: 14 February 2018 Published online: 27 February 2018

\section{References}

1. Guilhon J. Role of the Limacidae in the evolutive cycle of Angiostrongylus vasorum (Baillet, 1866). C R Hebd Seances Acad Sci. 1960;251:2252-3.

2. Barçante JM, Barçante TA, Dias SR, Vieira LQ, Lima WS, Negrão-Corrêa D. A method to obtain axenic Angiostrongylus vasorum first-stage larvae from dog faeces. Parasitol Res. 2003:89:89-93.

3. Mozzer LR, Montresor LC, Vidigal TH, Lima WS. Angiostrongylus vasorum: experimental infection and larval development in Omalonyx matheroni. J Parasitol Res. 2011;2011:1-4.

4. Mozzer LR, Coaglio AL, Dracz RM, Ribeiro VM, Lima WS. The development of Angiostrongylus vasorum (Baillet, 1866) in the freshwater snail Pomacea canaliculata (Lamarck, 1822). J Helminthol. 2015;89:755-9.

5. Aziz NAA, Daly E, Allen S, Rowson B, Greig C, Forman D, Morgan ER. Distribution of Angiostrongylus vasorum and its gastropod intermediate hosts along the rural-urban gradient in two cities in the United Kingdom, using real-time PCR. Parasit Vectors. 2016;9:56.

6. Coaglio AL, Mozzer LR, Negrão Corrêa D, Pereira CAJ, Lima WS. Evaluation of techniques for recovery of Angiostrongylus vasorum from Achatina fulica, a potential intermediate host. Rev Patol Trop. 2016:45:87-97.

7. Guilhon J, Cens B. Migrations and evolution of Angiostrongylus vasorum (Baillet, 1866) in dogs. C R Acad Sci Hebd Seances Acad Sci D. 1969;269: 2377-80. 
8. Pereira CA, Martins-Souza RL, Coelho PM, Lima WS, Negrão-Corrêa D. Effect of Angiostrongylus vasorum infection on Biomphalaria tenagophila susceptibility to Schistosoma mansoni. Acta Trop. 2006;98:224-33.

9. Pereira CA, Martins-Souza RL, Corrêa A Jr, Coelho PM, Negrão-Corrêa D. Participation of cell-free haemolymph of Biomphalaria tenagophila in the defence mechanism against Schistosoma mansoni sporocysts. Parasite Immunol. 2008;30:610-9.

10. Le Bris C, Paillard C, Stiger-Pouvreau V, Guérard F. Laccase-like activity in the hemolymph of Venerupis philippinarum: characterisation and kinetic properties. Fish Shellf Imm. 2013:35:1804-12.

11. Vargas-Albores F, Jiménez-Veja F, Yepiz-Plascencia GM. Purification and comparison of beta-1,3-glucan binding protein from white shrimp (Penaeus vannamei). Comp Biochem Physiol B Biochem Mol Biol. 1997;1 16:453-8.

12. Perazzolo LM, Barracco MA. The prophenoloxidase-activating system of the shrimp Penaeus paulensis and associated factors. Dev Comp Immunol. 1997;21:385-95.

13. Ashida M, Brey P. Recent advances on the research of the insect prophenoloxidase cascade. In: Brey PT, Hultmark D, editors. Molecular mechanisms of immune responses in insects. London: Chapman and Hall; 1998. p. 135-72.

14. Nappi AJ, Vass E, Carton Y, Frey F. Identification of 3,4dihydroxyphenylalanine, 5,6-dihydroxyindole, and N-acetylarterenone during eumelanin formation in immune reactive larvae of Drosophila melanogaster. Arch Insect Biochem Physiol. 1992;20:181-91.

15. Le Clec'h W, Anderson TJ, Chevalier FD. Characterization of hemolymph phenoloxidase activity in two Biomphalaria snail species and impact of Schistosoma mansoni infection. Parasit Vectors. 2016;9:32.

16. Söderhäll K, Cerenius L. Role of the prophenoloxidase-activating system in invertebrate immunity. Curr Opin Immunol. 1998:10:23-8.

17. Luna-Acosta A, Saulnier D, Pommier M, Haffner P, De Decker S, Renault T, Thomas-Guyon $\mathrm{H}$. First evidence of a potential antibacterial activity involving a laccase-type enzyme of the phenoloxidase system in Pacific oyster Crassostrea gigas haemocytes. Fish Shellf Imm. 2011;31:795-800.

18. Thurston CF. The structure and function of fungal laccases. Microbiology. 1994;140:19-26.

19. Nappi AJ, Vass E, Frey F, Carton Y. Nitric oxide involvement in Drosophila immunity. Nitric Oxide. 2000;4:423-30.

20. Dos Passos EM, Wanderley-Teixeira V, Marques EJ, Teixeira ÁA, Brayner FA. Cotesia flavipes (CAM) (Hymenoptera: Braconidae) supresses immune responses in Diatraea flavipennella (BOX) (Lepidoptera: Crambidae). An Acad Bras Cienc. 2014;86:2013-24.

21. Caldeira RL, Mendonça CL, Goveia CO, Lenzi HL, Graeff-Teixeira C, Lima WS, et al. First record of molluscs naturally infected with Angiostrongylus cantonensis (Chen, 1935) (Nematoda: Metastrongylidae) in Brazil. Mem Inst Oswaldo Cruz. 2007;102:887-9.

22. Maldonado A Jr, Simões RO, Oliveira AP, Motta EM, Fernandez MA, Pereira ZM, et al. First report of Angiostrongylus cantonensis (Nematoda: Metastrongylidae) in Achatina fulica (Mollusca: Gastropoda) from southeast and South Brazil. Mem Inst Oswaldo Cruz. 2010;105:938-41.

23. Hu X, Du J, Tong C, Wang S, Liu J, Li Y, He C. Epidemic status of Angiostrongylus cantonensis in Hainan Island, China. Asian Pac J Trop Med. 2011;4:275-7.

24. Vitta A, Polseela R, Nateeworanart S, Tattiyapong M. Survey of Angiostrongylus cantonensis in rats and giant African land snails in Phitsanulok Province, Thailand. Asian Pac J Trop Med. 2011;4:597-9.

25. Moreira VL, Giese EG, Melo FT, Simões RO, Thiengo SC, Maldonado A, Santos $\mathrm{JN}$. Endemic angiostrongylosis in the Brazilian Amazon: natural parasitism of Angiostrongylus cantonensis in Rattus rattus and R. norvegicus, and sympatric giant African land snails, Achatina fulica. Acta Trop. 2013;125:90-7.

26. Oliveira AP, Gentile R, Maldonado A, Lopes Torres EJ, Thiengo SC. Angiostrongylus cantonensis infection in molluscs in the municipality of São Gonçalo, a metropolitan area of Rio de Janeiro, Brazil: role of the invasive species Achatina fulica in parasite transmission dynamics. Mem Inst Oswaldo Cruz. 2015;110:739-44.

27. Lima WS, Araujo CHM, Guimarães MP, Leite AC. Angiostrongylus vasorum (Baillet, 1866) Nematoda: Prothostrongylidae em cães de Minas Gerais, Brasil. Mem Inst Oswaldo Cruz. 1985;80:233-5.

28. Bessa ECA, Lima WS, Daemon E, Cury MC, Araújo LB. Desenvolvimento biológico de Angiostrongylus vasorum (Baillet) Kamensnky (Nematoda, Angiostrongylidae) em Subulina octona Bruguière (Molusca, Subulinidae) em condiçōes de laboratório. Rev Bras Zool. 2000;17:29-41.

29. Alves CL, Araujo RN, Gontijo NF, Pereira MH. Importance and physiological effects of hemolymphagy in triatomines (Hemiptera: Reduviidae). J Med Entomol. 2011;48:372-81.
30. Carson FL, Martin JH, Lynn JA. Formalin fixation for electron microscopy: a re-evaluation. Am J Clin Pathol. 1973;59:365-75.

31. Plesh $\hat{A}$, Janse $\tilde{N}$, Boer H. Gross morphology and histology of the freshwater pulmonate Lymnaea stagnalis. Neth. J Zool. 1975;25:332-52.

32. Pan C. The general histology and topographic microanatomy of Australorbis glabratus. Bull Mus Comp Zool. 1958;119:235-99.

33. Sheehan DC, Hrapchak BB. Theory and practice of histotechnology. 2nd ed. St. Louis: CV Mosby Co.; 1980.

34. Seppälä $\mathrm{O}$, Leicht $\mathrm{K}$. Activation of the immune defence of the freshwater snail Lymnaea stagnalis by different immune elicitors. J Exp Biol. 2013;216:2902-7.

35. Vass E, Nappi AJ. Prolonged oviposition decreases the ability of the parasitoid Leptopilina boulardi to suppress the cellular immune response of its host Drosophila melanogaster. Exp Parasitol. 1998;89:86-91.

36. Nappi A, Poirié M, Carton Y. The role of melanisation and cytotoxic byproducts in the cellular immune responses of Drosophila against parasitic wasps. Adv Parasitol. 2009;70:99-121.

37. Binggeli $\mathrm{O}$, Neyen $\mathrm{C}$, Poidevin $\mathrm{M}$, Lemaitre B. Prophenoloxidase activation is required for survival to microbial infections in Drosophila. PLoS Pathog. 2014:10:e1004067.

38. Christensen BM, Li J, Chen CC, Nappi AJ. Melanization immune responses in mosquito vectors. Trend Parasitol. 2005;21:192-9.

39. Blasi E, Barluzzi R, Mazzolla R, Tancini B, Saleppico S, Puliti M, et al. Role of nitric oxide and melanogenesis in the accomplishment of anticryptococcal activity by the BV-2 microglial cell line. J Neuroimmunol. 1995;58:111-6.

40. Nappi AJ, Christensen BM. Melanogenesis and associated cytotoxic reactions: applications to insect innate immunity. Insect Biochem Mol Biol. 2005;35:443-59,

41. Lai SC, Jiang ST, Chen KM, Lee HH. Matrix metalloproteinases activity demonstrated in the infective stage of the nematodes, Angiostrongylus cantonensis. Parasitol Res. 2005:97:466-71.

42. Rebello KM, Siqueira CR, Ribeiro EL, Valente RH, Mota EM, Perales J, et al. Proteolytic activity in the adult and larval stages of the human roundworm parasite Angiostrongylus costaricensis. Mem Inst Oswaldo Cruz. 2012;107:752-9.

43. Brivio MF, Pagani M, Restelli S. Immune suppression of Galleria mellonella (Insecta, Lepidoptera) humoral defenses induced by Steinernema feltiae (Nematoda, Rhabditida): involvement of the parasite cuticle. Exp Parasitol. 2002:101:149-56.

44. Conejo ME, Morera P. Influência de la edad de los veronicelideos en la infección con Angiostrongylus costaricensis. Rev Biol Trop. 1988;36:519-26.

45. Barçante TA, Barçante JM, Dias SR, Lima WS. Angiostrongylus vasorum (Baillet, 1866) Kamensky, 1905: emergence of third-stage larvae from infected Biomphalaria glabrata snails. Parasitol Res. 2003;91:471-5.

46. Fang W, Xu S, Wang Y, Ni F, Zhang S, Liu J, et al. ES proteins analysis of Angiostrongylus cantonensis: products of the potential parasitism genes? Parasitol Res. 2010;106:1027-32.

47. Allam B, Raftos D. Immune responses to infectious diseases in bivalves. J Invertebr Pathol. 2015;131:121-36.

48. Yang B, Lu A, Peng Q, Ling QZ, Ling E. Activity of fusion prophenoloxidase-GFP and its potential applications for innate immunity study. PLoS One. 2013;8:e64106.

49. Yamazaki HI. The cuticular phenoloxidase in Drosophila virilis. J Insect Physiol. 1969;15:2203-11.

50. Neuhauss E, Fitarelli M, Romanzini J, Graeff-Teixeira C. Low susceptibility of Achatina fulica from Brazil to infection with Angiostrongylus costaricensis and A. cantonensis. Mem Inst Oswaldo Cruz. 2007;102:49-52.

51. Carvalho OS, Horácio TMS, Maria ME, Furtado MCLG, Leonel LH. Potentiality of Achatina fulica Bowdich, 1822 (Mollusca: Gastropoda) as intermediate host of the Angiostrongylus costaricensis Morera \& Céspedes 1971. Ver Soc Bras Med Trop. 2003;36:743-5. 